\title{
Designing an Undergraduate Engineering Mentoring Program to Enhance Gender Diversity through Application of Lean Six Sigma Methods and Tools
}

\section{Emily Kloos, University of Dayton}

Emily Kloos is a Graduate Assistant at the University of Dayton in the Department of Engineering Management, Systems \& Technology where she performs research in order to develop a STEM mentoring program for the University of Dayton. She has experience working as an engineer at various companies with a demonstrated history of working in the food production and manufacturing industries. Skilled in project management, customer service, food and beverage, wastewater treatment, and German language. She is a motivated individual with a Bachelor's degree focused in Mechanical Engineering from University of Dayton and working on a Master of Science degree in Engineering Management.

\section{Dr. Sandra L. Furterer, University of Dayton}

Dr. Sandy Furterer is an Associate Professor at the University of Dayton, in the Department of Engineering Management, Systems and Technology. She has applied Lean Six Sigma, Systems Engineering, and Engineering Management tools in healthcare, banking, retail, higher education and other service industries, and achieved the level of Vice President in several banking institutions. She previously managed the Enterprise Performance Excellence center in a healthcare system.

Dr. Furterer received her Ph.D. in Industrial Engineering with a specialization in Quality Engineering from the University of Central Florida in 2004. She received an MBA from Xavier University, and a Bachelor and Master of Science in Industrial and Systems Engineering from The Ohio State University.

Dr. Furterer has over 25 years of experience in business process and quality improvements. She is an ASQ Certified Six Sigma Black Belt, a Certified Quality Engineer, an ASQ fellow, and a certified Six Sigma Master Black Belt.

Dr. Furterer is an author or co-author of several academic journal articles, conference proceedings and 4 reference textbooks on Lean Six Sigma, Design for Six Sigma and Lean Systems, including her latest book: Lean Six Sigma Case Studies in the Healthcare Enterprise by Springer publishing in 2014. 


\title{
Designing an Undergraduate Engineering Mentoring Program to Enhance Gender Diversity through Application of Lean Six Sigma Methods and Tools
}

\begin{abstract}
Many female undergraduate Engineering students struggle during their first and second years of college with finding their place and questioning whether they belong in Engineering. It has been shown that mentoring programs can help encourage women to stay in engineering fields and we want to create a program at the University in the Women in Science and Engineering (WISE) program to retain more female engineering students. The purpose of this study is to apply Lean Six Sigma tools and methods to design an engineering undergraduate mentoring program to enhance retention of underrepresented females. As part of an engineering management graduate research project, the research assistant leveraged a team of students in the Industrial Engineering Technology program's undergraduate Lean Six Sigma course to design an engineering mentoring program. The course incorporates real-world lean six sigma experiential learning opportunities so that the students can better learn and apply lean six sigma tools and the DMAIC (Define-Measure-Analyze-Improve-Control) methodology. The team applied Voice of Customer to engage students and faculty to identify the pilot program's requirements. They used the lean six sigma process design tools and root cause analysis to identify the critical to satisfaction characteristics and the factors that will positively impact success of the mentoring program. This is a work in progress and constitutes the first step in designing and piloting an engineering mentoring program. The program will be piloted in Fall 2019, based on the findings from the Lean Six Sigma project. This program will provide mentorship to women engineers throughout their college career as well as support them for a career in engineering in the workplace.
\end{abstract}

Key words: Science, Technology, Engineering, Mathematics, STEM, Women, Minorities, Mentors, Education

\section{Introduction}

Many female STEM (Science, Technology, Engineering, Math) students struggle during their first and second year of college. They are unsure if they belong in STEM and look for encouragement to stay involved. According to previous studies, mentoring programs can help with these struggles and encourage women to stay in STEM. This paper will go into detail on the program to be designed at the university to enhance female participation in STEM by increasing retention rates as well as the overall number of female students in STEM at the university. This program will be able to provide the mentorship to keep female students motivated in STEM throughout their first year of college as well as prepare and support them for their remaining years in school. The University has about 10,000 undergraduates and about 3,000 graduate students. They have a very large School of Engineering, where 1 out of 6 students is in the school. They have large science, technology and math programs as well. The Women in Science and Engineering (WISE) program is a university program where students in science and engineering can interact with faculty, upper levels students, and professionals in these fields. 
The WISE program includes an Integrated Learning and Living Community ILLC). The WISE program is designed to provide support and community to women in engineering and science programs at the university [1]. There is a need for more women in STEM to increase diversity and fill the workforce needed to sustain current and future technology. Women are consumers, not just men, and their opinion should matter for products and services developed by engineers, scientists, mathematicians, etc. Women make up about $50 \%$ of university students across the United States and only 13 to $33 \%$ of those students hold a bachelor's or master's degree in STEM, with the lowest percentage in engineering degrees [2]. This research will look at the factors that contribute to lower numbers of female students in STEM and how perception and school experience can influence their confidence in studying STEM. The goals of this program will be to increase female participation in STEM, increase the number of women in STEM majors and to build confidence in first year female students to prepare them for a career in STEM. Prior to the pilot program being launched, a basis for what is needed will need to be created through past retention rates and root cause of why they leave STEM or are too afraid to enter these program. Students will be interviewed, and retention numbers will be evaluated including the following data from the last 3 years.

1) Number of female and male students that enter each STEM department their $1^{\text {st }}$ year at the university

2) Number of female and male students that remain in STEM at the start of their $2^{\text {nd }}$ year at the university

3) Number of female and male students in Engineering at the start of their $1^{\text {st }}$ and $2^{\text {nd }}$ year at the university

4) Number of female and male students that are not retained at the university from $1^{\text {st }}$ to $2^{\text {nd }}$ year

5) Retention rates for female and male students in STEM at the university

After the program has been implemented for 3 years, the student retention numbers will be reevaluated.

Background:

The current need for women in the STEM industry and the amount that are currently in the industry does not align. Many studies have been done to show the lack of women in leadership roles, the lack of gender equality and diversity in the workplace. But where do we start to increase those numbers? Female students and professionals in STEM often show selfdoubt in the STEM world. This doubt in their capabilities can often become frustrating and they tend to compare their success with the male students. Studies have shown that male and female students' abilities are the same, but females do not feel as confident as their male counterparts in class [4]. How do we make them confident in their major? Identifying this problem is a start to solving the overall problem.

After school programs and mentoring programs to build confidence in STEM have been implemented across the United States. Many programs have tried to decrease self-doubt. Research has shown that mentoring programs early on in a college career can increase the interest and retain those who are already in STEM. Female students with female peer mentors 
have shown to have a $100 \%$ retention rate [2]. Previous studies have shown research with peer to peer mentors as well as industry to student mentors. Both being successful in gaging interest in STEM. Schools across the country as early as kindergarten are working to close the gap on the number of female to male students in STEM with mentoring programs being very successful.

The University has various mentoring programs on campus but none that focus specifically on women in STEM. The Women in Engineering and Science (WISE) program administration has taken an interest in implementing the first pilot mentoring program for women in engineering and science. With their support, we will have the mentors and mentees needed to roll out a new program.

\section{Literature Review}

We will search the literature with respect to three areas that impact mentoring of women in engineering and science at the university level, 1) the lack of women in the work place in STEM fields; 2) the lack of confidence of women students in STEM fields; and 3) existing peer and industry mentoring programs in the literature.

\section{Lack of Women in the Work Place in STEM Fields:}

To develop a functioning mentoring program, we will have to first look at the statistics related to women in the pipeline in industry, as they move up in their careers. A study was done by LeanIn.Org and McKinsey \& Company understand how women move into management positions at lower percentages than men. Attrition, promotions, and hires during the years were calculated for women and men. Six employee levels were defined based on the employees' reporting structure, salary and advancement. These levels were divided into senior management, middle management and entry level. More than 34,000 employees across America took part in a survey of Human Resource (HR) practices [3]. Figure 1 shows the corporate pipeline in 2016 using the percent of male and female employees by level. The data demonstrate that there is a need to increase female employees in managerial levels and especially in the $\mathrm{C}$-suite of the workplace. In order to achieve managerial positions, one needs to be educated so it is necessary to look at the problems that exist prior to getting hired in the workplace that can contribute to lower percentages of women in engineering and science fields, including lack of confidence in studying in these fields.

\section{Lack of Confidence:}

Many female students are faced with the constant battle of self-doubt. Are they really capable of being in STEM? Do they belong with the other students? Universities have already started to look at these problems. A study was performed focusing on achievement goals and how they affect women in engineering as well as their perspectives on courses and experience compared to male students. The achievement goal theory is that those with low competence perceptions usually take on the avoidance achievement goals that avoid failure rather than focus on success. The two types of competence perceptions investigated were self-efficacy and perceived ability. The study was conducted to see if women in a freshmen engineering course would rate their competence lower than their male classmates and if they would be more likely to 
adopt avoidance achievement goals, having negative effects on grades and interest in freshman engineering courses. Six hypotheses were proposed: 1) female students would have lower levels of perceived ability, 2) female students would show lower self-efficacy, 3) female students would have higher levels of performance-avoidance goals, 4) female students would have higher levels of mastery-avoidance goals, 5) females would have lower course grades and 6) females would have lower course interest [4].

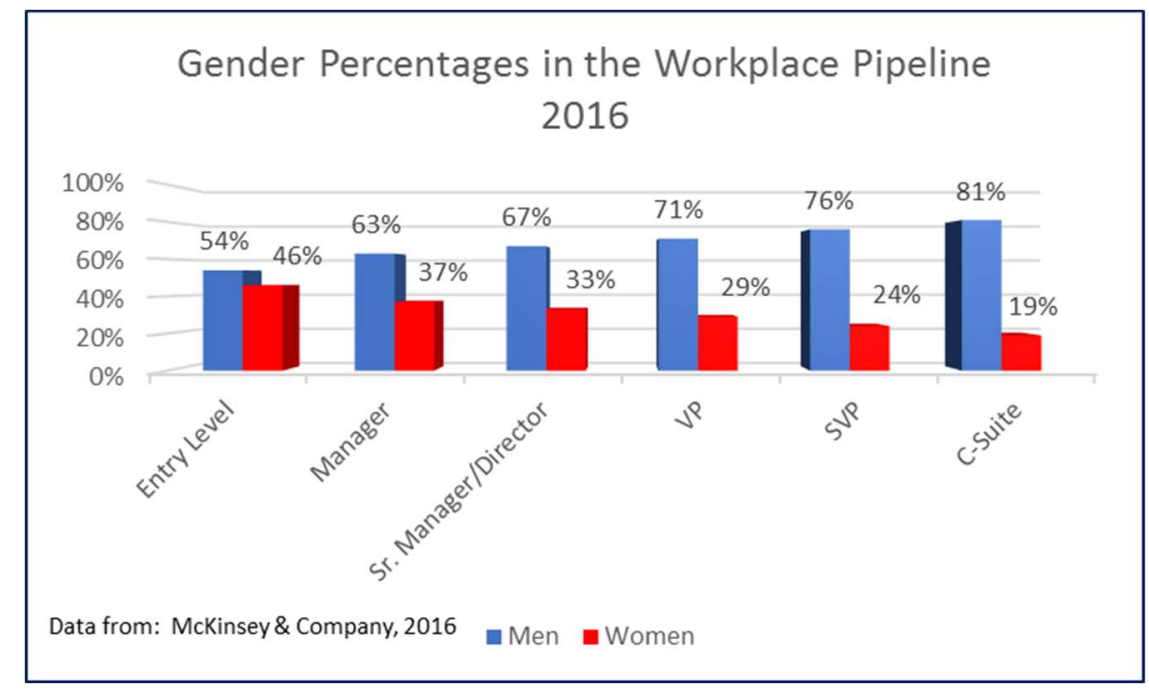

Figure 1. Percent of employees by gender and level [3]

Hypotheses one through four were proven to be consistent with the data collected from the three surveys. Women showed lower perceived ability, self-efficacy, performance approach and mastery approach than men. They also showed a higher performance avoidance and mastery avoidance than men. Although hypotheses one through four proved to be true, five and six showed different results than expected. From the significant data collected, course grade and interest were not affected by the negative achievement goals that women demonstrated. The results actually showed women to have a higher grade and interest in the course. This means that even though women demonstrate a lack of confidence and self-efficacy in engineering, they are still able to learn the material just as well as men. Although lack of confidence does not always affect one's grades or retention in STEM, building up their confidence will be important in retaining and bringing in more female STEM majors.

\section{Mentoring Programs:}

Schools across the United States are working to retain students in science, technology, engineering and mathematics by using peer and professional mentoring programs. One article studied mentoring female first year engineering students. In this study, they wanted to make female students feel a sense of belonging. Trained mentors met monthly with female engineering students and surveys were performed that looked into sense of belonging, confidence, motivation, anxiety and retention as well as career paths in engineering. It was found that female students felt more confident in their ability as well as belonging in engineering when they had a female peer mentor. Females without a female mentor felt less confident, less motivated, and showed less interest in Engineering. The results showed a 100\% 
retention rate for those with female peer mentors, $82 \%$ retention rate with male peer mentors, and an $89 \%$ retention rate with no peer mentor [2]. It is interesting to see that those who had a male peer mentor had a lower retention rate than those with no mentor. The program at the university will focus on using female mentors.

Another article found that peer mentoring teams that met monthly throughout the semester found a "... slight improvement in metacognitive strategies, goal orientation, resource management and academic performance" [7]. A graduate student peer mentoring program provided positive results in helping to address challenges faced by women in engineering, such as "... barriers of isolation and lack of successful role models at the graduate level" [8]. A program at the University of Toledo focused on retention of women in science and engineering and incorporated a peer mentoring program, connecting freshmen women students with senior students. The program helped women to provide balance between their academic work and their engagement in the wider university community. It also provided opportunities to see women role models [9].

Less than $40 \%$ of students who began their college career as a STEM major, complete their bachelors in STEM [5]. At Northern Kentucky University, a research study was done by using student STEM ambassadors to increase retention rates by utilizing study sessions, building a STEM community, developing a recruiting strategy and encouraging undergraduate research. The researcher's University is all about community. If we can incorporate some of the techniques that were used at NKU, more students would want to be involved in the STEM majors. There is a current stigma that it is uncool or not very fun to be involved in the STEM activities. By creating a community, more students will want to be included in the events and activities.

A student ambassador program was launched at NKU in the 2010-2011 school year and included 15 student ambassadors that were compensated for each semester. The ambassador roles included leading undergraduate study sessions, organizing social events, conducting and participating in project meetings and representing the STEM departments at recruitment events. These responsibilities all tie into their own Leadership Development as well. Each ambassador is trained in interpersonal and intrapersonal skills, self-leadership skills, engagement, people complexity as well as communication and organization skills. The WISE program at the university has leaders for women in science and engineering. It is possible to expand these leaders to technology and mathematics departments. Further training will need to be done and more mentors would need to be found to represent the technology and mathematics departments.

The outcomes of the program at NKU focused on three main values: 1) student participation and perceptions, 2) retention and 3) student ambassador development. All three are valuable in creating a working mentoring program. The annual participation in the program increased from 1523 students in the 2010-2011 school year to 1764 students in the 2013-2014 school year [5]. The school wanted results sooner than they could gather them, so to gain immediate feedback on the progress of the program, surveys were sent out to the students to comment on the effectiveness of the program. Surveys were also sent out in evaluating the study sessions, interactions with the ambassadors, and perceptions of the ambassadors. The responses 
were very positive and helpful in continuing the program. Students rated questions based on a scale of strongly agree (5), agree (4), neutral (3), disagree (2) and strongly disagree (1). By the spring of 2014, enough data had been collected to compare retention results between students in the program, students who participated in a few social activities, and those who were not involved. Retention was higher when involved in these mentoring programs. This article is a great baseline for an effective program that can be utilized at the University using the current student leaders and recruiting more to utilize each STEM department.

Statistics show that 300,000 STEM degrees are awarded in the United States annually, but about one million more will be needed in the next decade, which calls for about a $34 \%$ increase annually [6]. The University of Hartford has created a program called STEM UP! It uses young STEM professionals to mentor students in the area. A study was performed using three public middle and high schools in Hartford. The schools were a multicultural suburban high school, a suburban public high school (90\% Caucasian), and a charter school. Sessions were held with students one afternoon per week. During these sessions, they would take real world applications and create items based on the mentor's profession. An example would be a biomedical engineer had the students create a functioning hand out of paper, cardboard and other pieces. Therefore the students could see the importance of their job and gain their interest.

The students were asked if they thought they would pursue a career in STEM prior to the sessions and after the sessions had ended. There was about a $25-30 \%$ increase in the students saying yes to STEM after they had learned more about it. Surveys were also done to gage the students' interest and confidence in the STEM subjects. Many students showed a better understanding and a positive outlook in STEM after the sessions. Although this study does not directly relate to the program being started at the university, it gave some great insights on the effects of mentoring and professional mentoring of students. It would be beneficial for students to become familiar with their role in a STEM career and be able to see examples by professionals along with advice. This would be a great next step for the program once it is up and running.

\section{Methodology}

In order to launch a functioning program, data was collected to find the need and what sources were available to implement such a program. Data collection was done using three types of data: 1) literature search and review; 2) interviews and surveys; and 3) data collection of retention numbers. The literature search consisted of articles found through the university's online library search tool as well as articles previously read and reviewed in the Enhancing Leadership and Engagement for Diversity class offered at the university. The literature search was crucial in identifying the problem as well as finding current successful programs at other schools across the United States. These articles showed programs in different levels of education ranging from kindergarten to college as well as using peer to peer mentors and industry mentors. The articles used were current topics within the last decade. After reviewing previous work, it was time to take the ideas to the people at the university.

Students and faculty were interviewed on the current programs offered at the university for mentorship as well as what they would like to see in a mentoring program. Faculty members were asked about current programs in place and where to start for the STEM students. Their 
ideas were helpful in determining the right group of pilot program students. Voice of customer was collected from a small group of first year STEM students in the Women in Engineering and Science (WISE) program. WISE is part of an Integrated Living and Learning Community and includes students with engineering, biology, chemistry, pre-physical therapy and pre-medicine majors. This is a perfect starting point for a pilot program. From this focus group, the voice of customer was collected to determine the critical to satisfaction factors. The Critical to Satisfaction (CTS) criteria for retention rate increases are shown in Figure 2, the CTS tree, below.

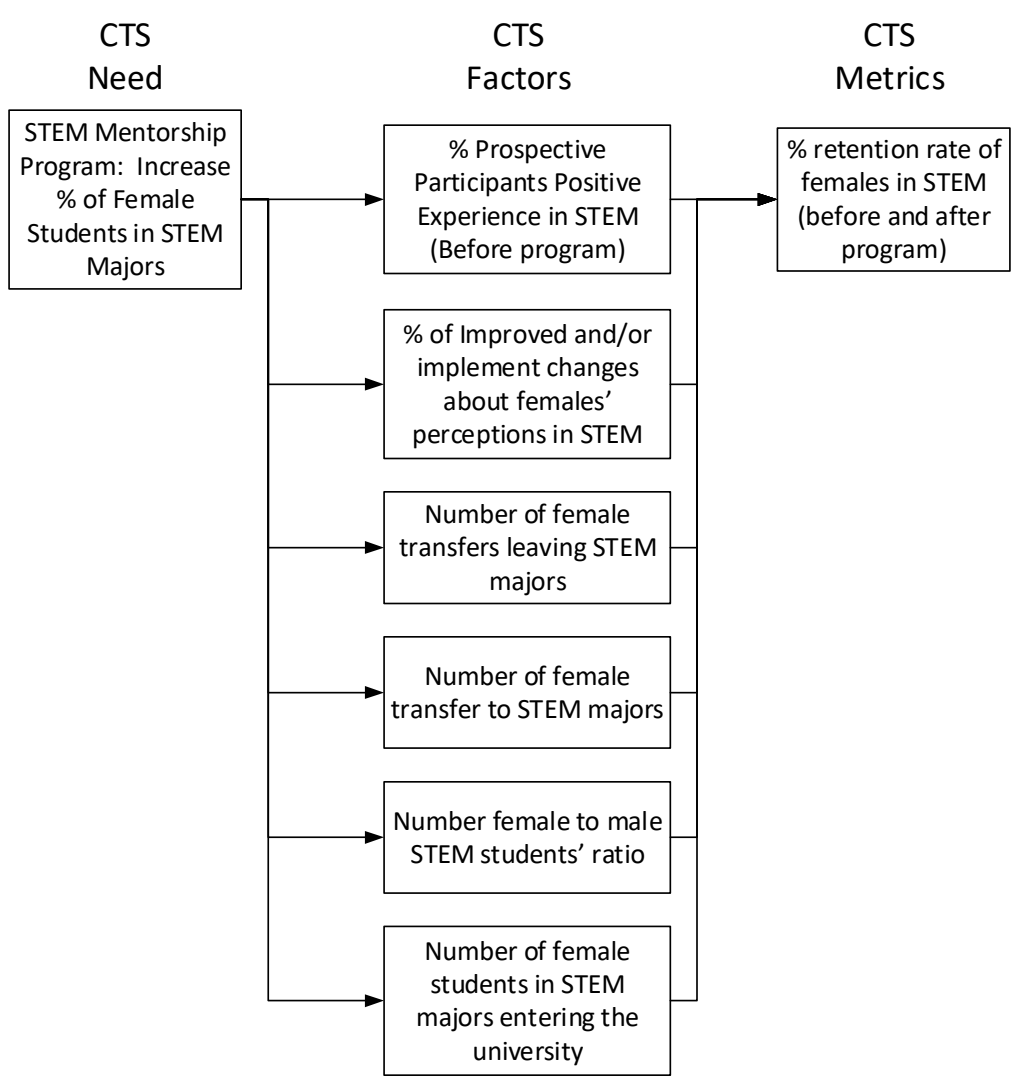

Figure 2. CTS need for increased retention of female students in STEM

The data collected included the retention numbers from the last 3 years in STEM majors for female and male students. A total of 25 majors were analyzed. Each major is included in engineering or science departments, with mathematics and technology included in those departments. Three years of data showed the freshman entering into each program and how many of those students remained in that major during their second-year census. To get an idea of where the female student numbers need to be, the male student numbers were also analyzed. The charts included showed various results such as decrease in students by major, comparison of female to male students in STEM and engineering specifically as well as those not retained.

Additionally, nineteen female WISE group students were surveyed with 10 open ended questions on their thoughts of a mentoring program. Figure 3 shows the percentage of each major of the students that filled out the survey. When asked if the students were interested in a 
mentoring program, most of the students wanted to be a part of the pilot program. This data can be found in Figure 4.

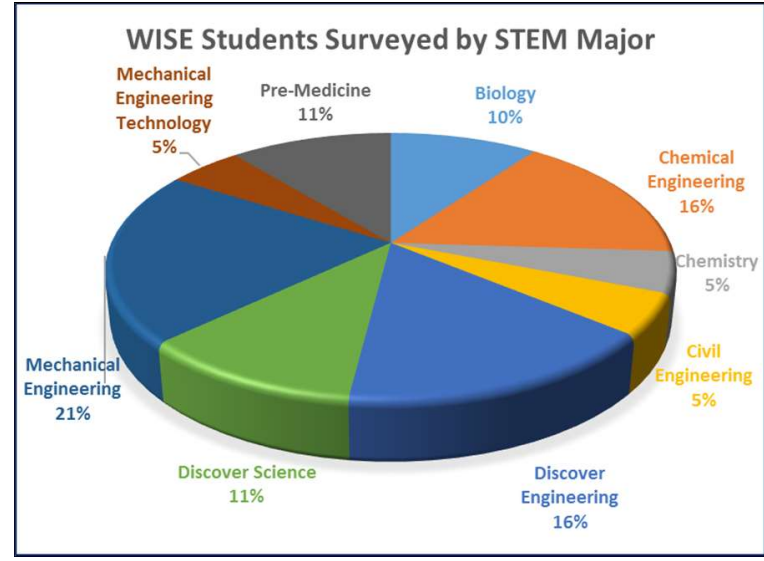

Figure 3. WISE students surveyed by STEM major

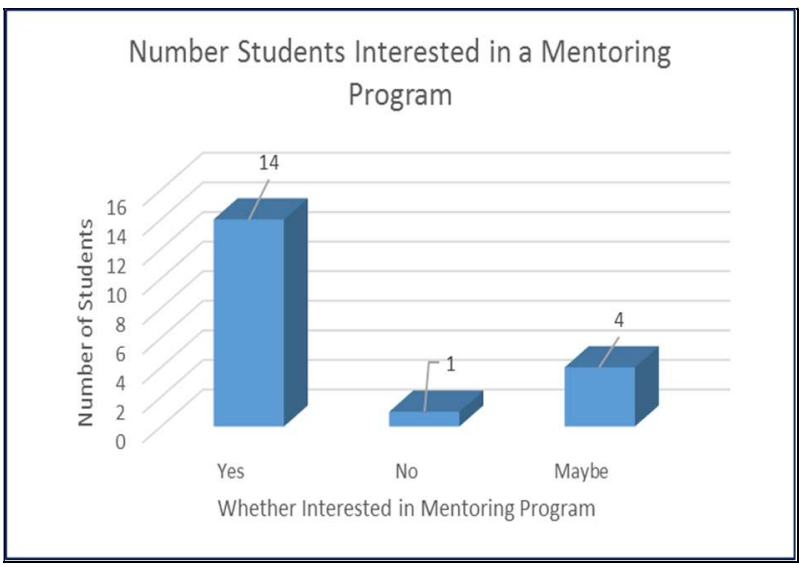

Figure 4: Number of students interested in pilot program

The retention data received from the analytics department at the university was used and plotted in various ways to show the impact of a student's first year to second year in STEM. To get an overall view, the average number of students for each category during the three years was calculated to compare female and male students. Figure 5 makes it very easy to see the lack of female students in STEM majors at the university.

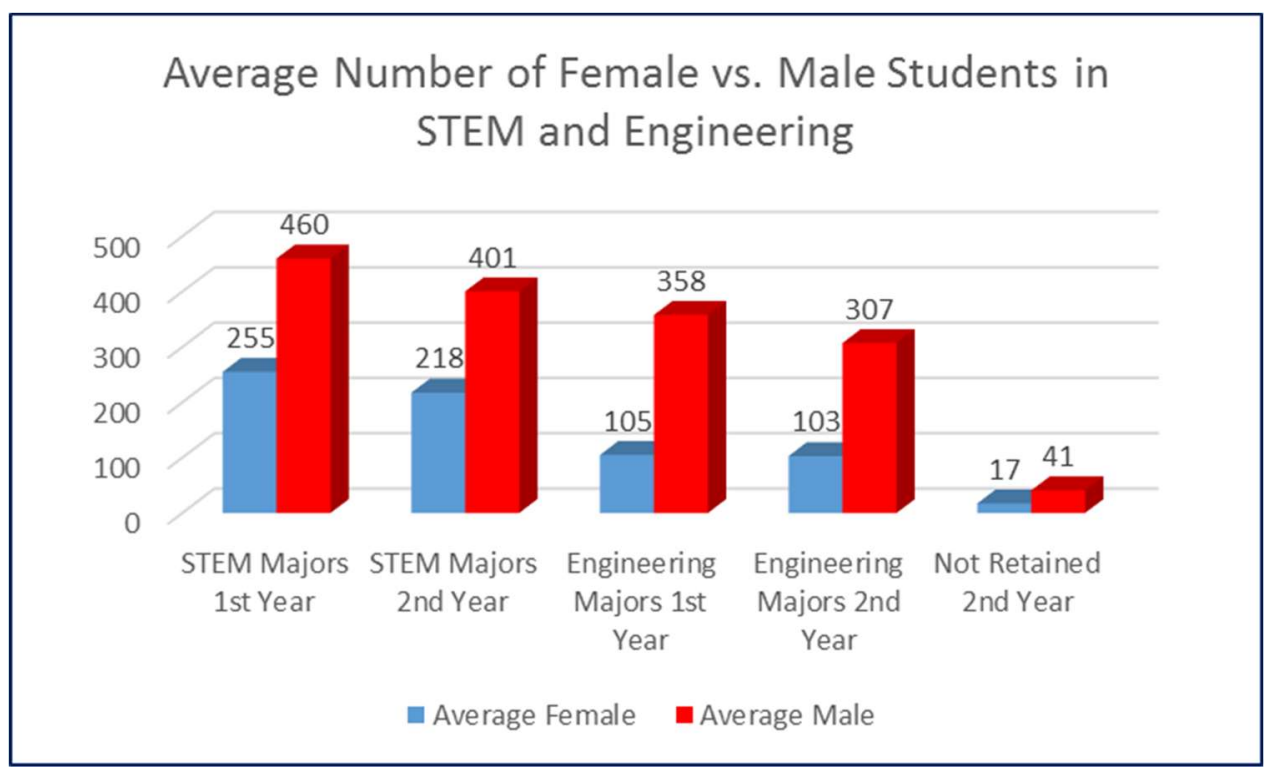

Figure 5. Female students in STEM and engineering by year

Prior to implementing a pilot program, it is valuable to create a process map to create a potential future pilot program. The process maps were created by the Lean Six Sigma project team in the undergraduate "Lean Management and Six Sigma" course at the university. The process maps include the process for the program lead, mentors and mentees. The lead process 
map shows the overall program map starting with a program lead to implement the program. Once the program lead has been assigned, the program will need to be advertised in order to find the program mentors. This will be done through the WISE program, and has already started by introducing the $1^{\text {st }}$ year students to the program idea. Mentors and mentees will be paired up and will be survey on their satisfaction with the program throughout the semester. Each mentor will be trained prior to the Fall 2019 semester. Applications will be due during the Spring 2019 semester and the students will have their first meeting prior to leaving for the summer. A week prior to the Fall 2019 semester, the mentors will return to school to be trained in leadership skills. The last process map contains the steps necessary for mentees in the program. They will be able to sign up in the beginning of the Fall 2019 semester and will get to meet the possible mentor candidates within the first couple of weeks of being on campus.

After meeting with the Fall 2018 1st year WISE students, a few improvement factors were identified to improve their first semester. These factors included: 1) monthly tutoring sessions with other WISE students; 2) more Supplemental Instruction (SI) sessions for their 1st year courses; 3 ) monthly face to face meetings with a mentor in the WISE program; and 4) more time to work in groups that share similar course schedules.

From the focus group meeting and surveys collected, 3 Why-Why diagrams were created. The purpose of these diagrams was to perform a root cause analysis on the potential problems within the process. The diagrams are based on the concept of "using five whys" for five iterations in a method with the idea that the root cause of the problem can be identified, and the problem can be fixed. Since the program has not been piloted yet, why-why diagrams were used to explain the hypothetical whys of the program. Figure 6 below shows the root cause analysis for the low proportion of female to male students in STEM during the timeframe of the Fall 2018 semester. This figure was created by the undergraduate "Lean Management and Six Sigma" course team.

During this study and pilot program the goal is to increase the number of female students in STEM by increasing the participation of these students on campus and keeping them interested in staying in STEM. Variables will include the incoming STEM student size each fall semester by gender and those that remain in STEM through the September census each fall. This will show those students that are dedicated to stay in STEM their first semester Freshman year. Another area we want to evaluate is the ratio of female to male students in STEM every fall semester for the next 3 years (2019-2021) to compare to the previous data (2015-2017) analyzed this semester. This will show if the gap between female and male STEM students is starting to close. Another variable to evaluate will be the majors within STEM to determine factors that contribute to students leaving STEM. This will show us what majors struggle the most in growing and retaining students. The retention rates will be evaluated as a whole as well as by major. Statistics will be plotted accordingly to the charts in the data collection section from the current data received by the analytics department. 


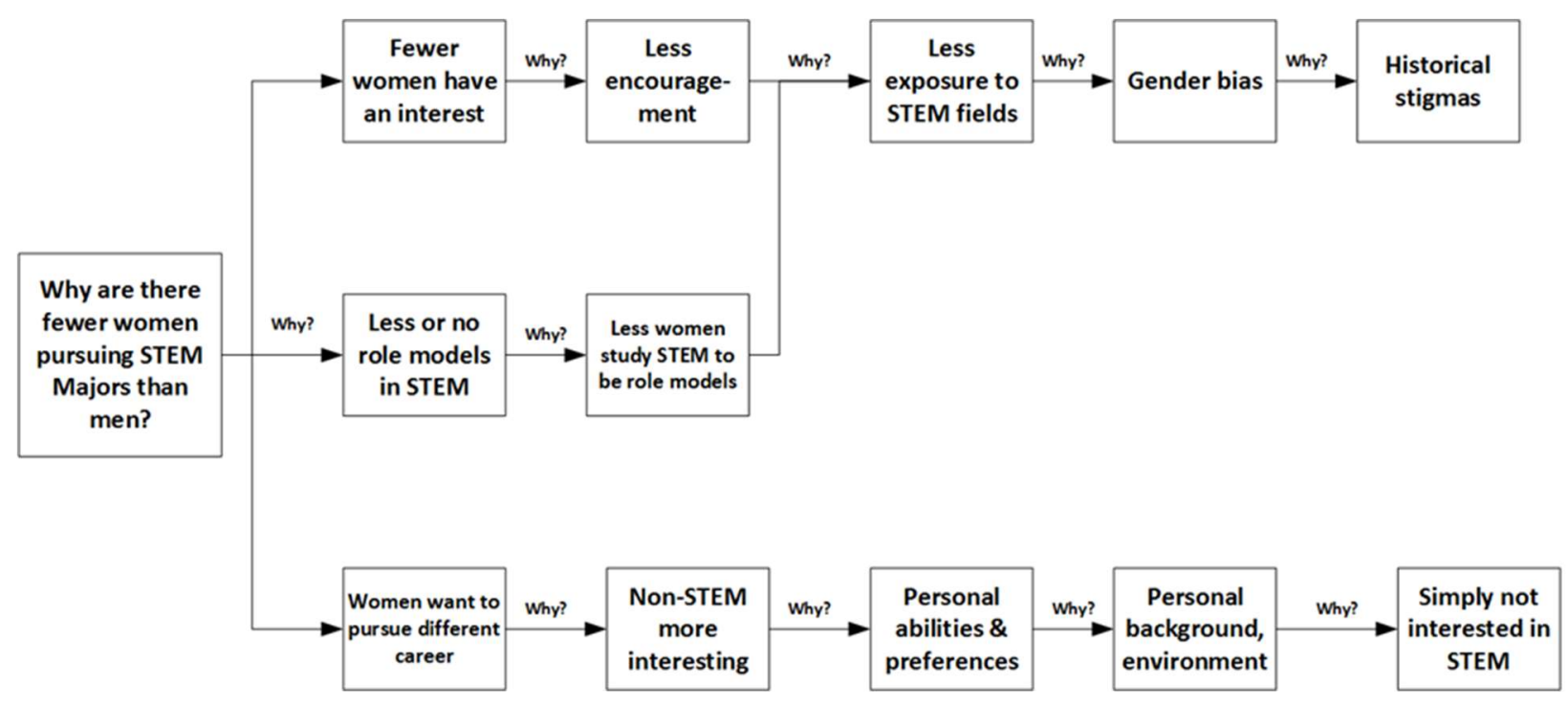

Figure 6. Why-Why Diagram of Low Proportion of Female to Male Students in STEM

The Quality Function Deployment (QFD) House of Quality was used to ensure alignment between the Critical to Satisfaction (CTS) characteristics which represent the customers' requirements and the improvement ideas, representing the technical requirements, as shown in Figure 7. The CTS' included: 1) the mentors and mentees meeting several times each semester; 2) increasing the students' retention rate in their programs; and 3) mentors' and mentees' satisfaction with the mentoring program. The improvement ideas included: 1) the mentors and mentees being actively engaged during mentoring meetings; 2) the mentors providing advice to the mentees to guide their academic success; 3 ) standardizing google forms to track the metrics for the mentoring program; and 4) having a strong mentoring administration presence. The highest ranked improvement idea was to implement a mentoring program that enabled the mentors and mentees to be highly engaged with each other.

The data from the analytics department shows us that there is a need to increase the female STEM population at the university. It is assumed by this data and the previous research done in mentoring programs that if the program is successful, more females will join the program and bring in more female STEM students in the future. Factors that will be key to success will include the following:

- Increase participation in WISE group

- Mentor satisfaction with the program

- Mentee satisfaction with the program

- Build a community of STEM female students

Visio will be used to setup the final process map for each part of the program. Excel will be used to plot the data to compare to the data collected from previous years. 


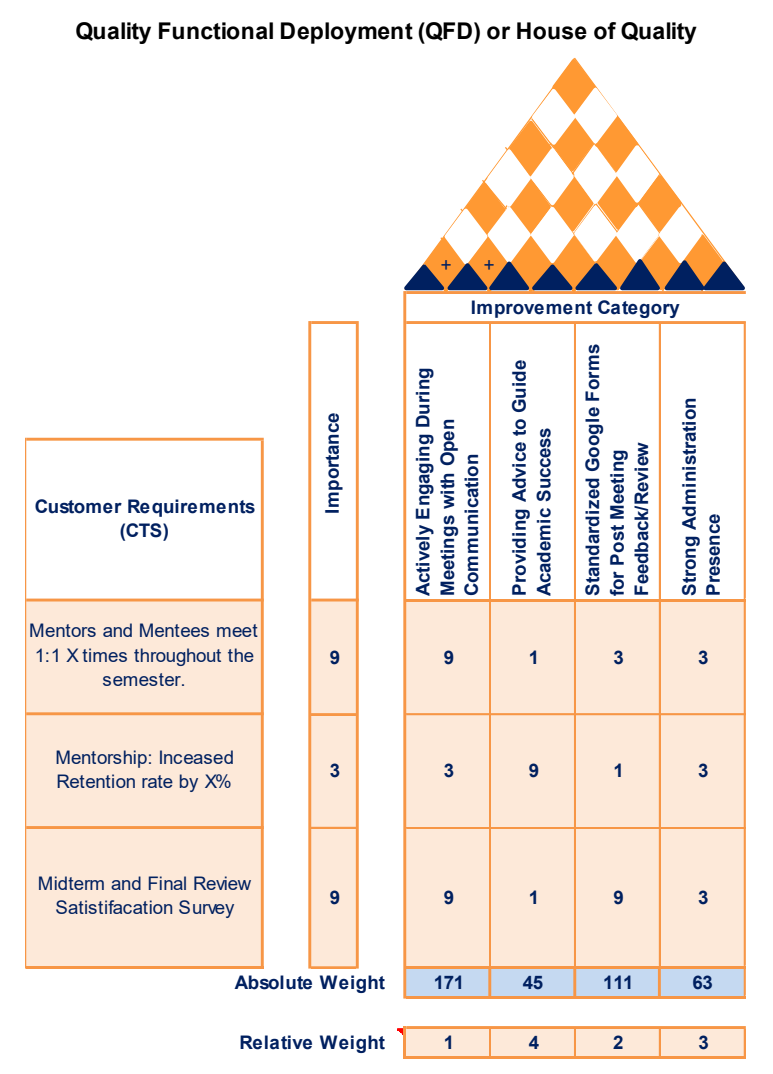

Figure 7: Quality Function Deployment, House of Quality

Surveys will be sent out monthly to test the program's success. The percent of response will be calculate from the data set of a survey with a 5-point scale. The same survey will be sent out monthly to the same group of students to compare results throughout the semester.

The pilot program validation was done by holding a focus group with current $1^{\text {st }}$ year students in the WISE program. The students were interested in the program and saw its worth to incoming freshman. They also showed interest in becoming a mentor their $2^{\text {nd }}$ year at the university. The metrics will be validated by analyzing the number of students retained each year from freshman to sophomore year while the program is in place and comparing those numbers to the ones from previous years prior to the program. Even though the program will not convince all to stay in STEM, it should have an effect on the number of female students that remain in STEM and enter STEM each year. A program must be established before it gains interest of those who were originally not interested in STEM or those who were not interested in STEM at the university. Creating a reputation will help those numbers in the end.

\section{Conclusions}

The research done this semester gives a baseline for what should be included in the mentoring program for Fall 2019. It was shown that students want a mentor during their first year and that there is an opportunity to improve the number of female students in STEM and to retain those students. Students are looking for direct access, a community, and someone who understands their current struggles when adjusting to a new school. By introducing mentors to 
first year students, we can help with the first-year struggles and give the direct access they need as well as a friend to show them around the school and get them accustomed to a new place. These steps will help make students feel more welcome and with time increase the number of females in STEM at the university. The students will share their own positive experiences with other future students and encourage more females to join STEM and stick with it. This program is a great opportunity at the university and will build a future for females in STEM.

\section{Future Work}

This paper described the methodology and results of the design of a mentoring program for women in Engineering and Science. The researchers applied Lean Six Sigma (LSS) in an undergraduate course. The LSS method enabled the collection of the Voice of the Customer (VOC), women in engineering and science at the university. It also provided a baseline of the number of women students currently enrolled in STEM majors and their retention rates for the first and second years in their majors. The next steps are to organize and implement a pilot mentoring program within the WISE program, for Fall 2019. We are additionally investigating both internal and external funding options for the program and future research.

\section{References}

[1] No Author, "Integrated Living Learning Communities, Women in Engineering and Science. " https://udayton.edu/1lc/integrated_1lcs/women_in_science_engineering_1lc.php.

Accessed March 17, 2019.

[2] No Author, "Female Peer Mentors Help Retain College Women in Engineering." Education Digest, vol. 86, no. 4, Dec. 2017, p. 30.

EBSCOhost,libproxy.udayton.edu/login?url=http://search.ebscohost.com/

login.aspx?direct $=$ true $\& \mathrm{db}=\mathrm{f} 5 \mathrm{~h} \& \mathrm{AN}=125896865 \&$ site $=$ eds-live. Accessed January 30, 2019.

[3] No Author, "Women in Workplace 2016", McKinsey \& Company, LeanIn,

[4] CM. JAGACINSKI, "Women Engineering Students: Competence Perceptions and Achievement Goals in the Freshman Engineering Course." 2013;(11-12):644. http://libproxy.udayton.edu/login?url=https://search.ebscohost.com/login.aspx?direct=tr $\mathrm{ue} \& \mathrm{db}=$ edsfra \&AN=edsfra.27976806\&site=eds-live. Accessed January 30, 2019.

[5] B. Bowling, M. Doyle, J. Taylor, and A, Antes, "Professionalizing the Role of Peer Leaders in STEM." Journal of STEM Education: Innovations and Research, 16(2), 30-39, 2015. Retrieved from http://libproxy.udayton.edu/login?url=https://search.ebscohost.com/login.aspx?direct=tru $\underline{\mathrm{e} \& \mathrm{db}=\text { eric } \& \mathrm{AN}=\mathrm{EJ} 1070122 \& \text { site }=\text { eds-live }}$

[6] A Ilumoka, I. Milanovic, and N. Grant, “An Effective Industry-Based Mentoring Approach for the Recruitment of Women and Minorities in Engineering." Journal of STEM 
Education: Innovations and Research, 18(3), 13-19, 2017. Retrieved from http://libproxy.udayton.edu/login?url=https://search.ebscohost.com/login.aspx?direct=tru $\underline{\mathrm{e} \& \mathrm{db}=\mathrm{eric} \& \mathrm{AN}=\mathrm{EJ} 1156917 \& \text { site }=\mathrm{eds}-\mathrm{live}}$

[7] JL Sliko, A. Morales, S. Agili, R.Asempapa, "Keeping women in stem majors: the penn state Harrisburg stem scholars program.” Abstracts with Programs - Geological Society of America. 2018;50(6):@Abstract no. 103-3.

http://libproxy.udayton.edu/login?url=https://search.ebscohost.com/login.aspx?direct=tru $\mathrm{e} \& \mathrm{db}=$ guh\&AN=844143-50\&site=eds-live. Accessed March 17, 2019.

[8] S. Bhatia S, JP Amati, "If These Women Can Do It, I Can Do It, Too": Building Women Engineering Leaders through Graduate Peer Mentoring. Leadership \& Management in Engineering. 2010;10(4):174.

http://libproxy.udayton.edu/login?url=https://search.ebscohost.com/login.aspx?direct=tr $\mathrm{ue} \& \mathrm{db}=\mathrm{edb} \& \mathrm{AN}=53711711 \&$ site=eds-live. Accessed March 17, 2019.

[9] Franchetti M., “An Analysis of Retention Programs for Female Students in Engineering at the University of Toledo. Journal of Pre-College Engineering Education Research." 2012;2(1):21-27.

http://libproxy.udayton.edu/login?url=https://search.ebscohost.com/login.aspx?direct=tr $\mathrm{ue} \& \mathrm{db}=$ eric \&AN=EJ1056114\&site=eds-live. Accessed March 17, 2019. 